Declaration of interest

Submission made on behalf of the Executive Committee of the Royal College of Psychiatrists' Section of Neuropsychiatry.

1 Oakley C, Jenkinson J, Oyebode F. Psychiatric training for the next generation. Psychiatrist 2013; 37: 25-9.

2 Silver JM. Behavioral neurology and neuropsychiatry is a subspecialty. J Neuropsychiatry Clin Neurosci 2006; 18: 146-8.

3 Agrawal N, Fleminger S, Ring H, Deb S. Neuropsychiatry in the UK: planning the service provision for the 21st century. Psychiatr Bull 2008; 32: $303-6$

4 Arambepola NMA, Rickards H, Cavanna AE. The evolving discipline and services of neuropsychiatry in the United Kingdom. Acta Neuropsychiatr 2012; 24: 191-8.

5 Earl J, Pop O, Jefferies K, Agrawal N. Impact of neuropsychiatry screening in neurological in-patients: comparison with routine clinical practice. Acta Neuropsychiatr 2011; 23: 297-301.

Rory Conn, CT3 Psychiatry, Camden and Islington NHS Foundation Trust, London, UK, email: rconn@doctors.org.uk; Andrea E. Cavanna, Consultant in Behavioural Neurology, Birmingham and Solihull Mental Health NHS Foundation Trust, UK, Honorary Reader in Neuropsychiatry, University of Birmingham, UK, and Visiting Professor in Neuropsychiatry, University of Pavia, Italy.

doi: $10.1192 / p b .37 .4 .147 a$

\section{Psychiatrists are not surgeons}

Reading the article by Archdall et al took us right back to our student days, where we both remember our emerging interest in psychiatry often being lambasted by those around us. Not so reassuring to see that some things never change.

What was most striking then, and it appears still now, are the beliefs that 'you can't cure anyone if you do psychiatry', 'you can't help people'. While we admit it has been a few years since either of us have worked in acute medicine or primary care, unless there have been some radical developments, we were not aware that conditions such as asthma, diabetes, arthritis or coronary artery disease could be easily cured either. Yet chronic physical illness is what the majority of medical students will end up managing in some form or another.

This research made us wonder whether we as psychiatrists paint a rather grave, dare it be said hopeless, picture of what our specialty involves when students spend time with us. Because surely the reality is that psychiatry has no lower a 'help' rate than other specialties that deal with both acute and chronic illness?

We did not go into medicine solely to cure people; we went into medicine to help ease suffering, in whatever small way that may be. And yes, that may be a listening ear instead of a scalpel or a pill, but no less is the satisfaction for us or relief for the patient.

So what is the answer to this? How do we help students see psychiatry for what it is, rather than this hopeless and helpless version that keeps being quoted back to us? We suggest addressing this stigma head on, acknowledging that we are seen as separate and different, and take students to see the good that we do.

1 Archdall C, Atapattu T, Anderson E. Qualitative study of medical students' experiences of a psychiatric attachment. Psychiatrist 2013; 37 $21-4$.
Eleanor J. Hogarth, ST4 in forensic psychiatry, email: Eleanor.Hogarth@ awp.nhs.uk, and Elizabeth O'Mahony, ST5 in forensic psychiatry, both at Fromeside, Blackberry Hill Hospital, Stapleton, Bristol, UK.

doi: $10.1192 / p b .37 .4 .148$

\section{Psychiatry tasters are needed early in foundation training}

As a core psychiatric trainee with an interest in recruitment whose decision to enter psychiatry was influenced by completing a Foundation Year 2 (FY2) post in the specialty, I read the article by Kelley et al ${ }^{1}$ with interest. The study showed a significant association between undertaking a Foundation Programme placement in psychiatry and entering core psychiatric training. One problem of the study, acknowledged by the authors, is that it did not look at the career preferences of the participants. As the authors admitted, it is likely that many of the doctors completing foundation placements in psychiatry already had a prior interest in it, and were therefore more likely to express a preference for, and be allocated to, programmes containing a rotation in psychiatry. Further research is therefore needed to evaluate further the influence of a foundation placement in psychiatry on eventual career choice, before we can infer that there is a causal link.

Given that the application process for core training begins in November, only those doctors completing an FY2 post in psychiatry within the first rotation of their FY2 year would experience psychiatry before applying for specialty training. This serves to highlight the potential value of tasters in allowing FY2 trainees to gain some experience in psychiatry before the application period.

Although I am in agreement that an increase in the number of foundation placements in psychiatry is important, I also believe that it is important to focus on attracting medical students to psychiatry at an earlier stage and ensuring that we do all we can to provide high-quality undergraduate training and placements in psychiatry, so that newly qualified doctors already have an interest in psychiatry before entering foundation training and have already thought about it seriously as a career choice.

1 Kelley TA, Brown J, Carney S. Foundation Programme psychiatry placement and doctors' decision to pursue a career in psychiatry. Psychiatrist 2013; 37: 30-2.

Thomas J. Burden, Core Trainee CT2, Cardiff and Vale University Health Board, Cardiff, UK, email: thomasburden@doctors.org.uk

doi: $10.1192 / p b .37 .4 .148$

\section{Influence of foundation job subspecialty}

I read with interest Kelley et al's article, ${ }^{1}$ particularly in light of previous correspondence in The Psychiatrist regarding whether some subspecialties are better with foundation doctors. I am a CT3 in psychiatry, with a hope to specialise in old age. During my foundation jobs I had a 4-month rotation working with general adult in-patients. I am perhaps not best placed to comment on the influence of which subspecialty of foundation job best influences recruitment to psychiatry as a whole, given that my decision to go into psychiatry was made even before entering medical school, however, I have been struck by the 
different experiences my foundation doctor colleagues (and also undergraduates on their attachments) have had depending on whether they are working in general adult or old age psychiatry.

That recruitment into psychiatry is a problem is not news and the Royal College of Psychiatrists has launched a 5-year plan to increase applicants to psychiatry. ${ }^{2}$ The reasons for this have been argued as being multifactorial, ${ }^{3}$ however, a large part appears to be the view that psychiatry is an 'inferior' specialty, that psychiatrists become 'deskilled' in their medical knowledge and that, with New Ways of Working, consultant psychiatrists may feel disempowered, with less control of their workload leading to greater stress and reduced job satisfaction. There is also a feeling of psychiatry being somewhat separate from the other medical specialties. Most mental health services are run out of separate hospitals, and indeed separate trusts, and medical students and other doctors rarely see psychiatrists in ward rounds.

The viewpoint of those who have done a foundation job in old age psychiatry, however, appears to be somewhat different. Admittedly, my impression has been formed only through informal discussions about a subspecialty to which I am already committed. As the medic in the team, foundation doctors experience the more complex patients and are required to keep their skills up to date regarding the medical needs of patients, either as in-patients, out-patients or in liaison services. They are often required to liaise with teams based in the general hospital on the care of patients, who, by the nature of the specialty, often have a variety of health problems, particularly neurological, given the overlap in presentation. They have the opportunity to be involved in liaison work and therefore have face-to-face contact with colleagues in other specialties, thus preventing the feeling of separateness and isolation from other disciplines. Although emphasis is still on multidisciplinary team working, each member of the team, including the consultant, has individual roles depending on their skills and job title. They therefore see the consultant of the team being treated with the realisation that their skills are better used for diagnosis, treatment, clinical decision-making and leadership of the team while drawing on the skills of other professionals.

Barras \& Harris ${ }^{4}$ have commented that if attrition from psychiatry is to be minimised, issues such as how psychiatric trainees integrate with other medical specialties, and how the role of doctors in the specialty is perceived need to be addressed, and I would certainly agree. What retained me in working in psychiatry at a time when New Ways of Working and exam pressures were resulting in demoralisation, was my experience in old age psychiatry.

1 Kelley TA, Brown J, Carney S. Foundation Programme psychiatry placement and doctors' decision to pursue a career in psychiatry. Psychiatrist 2013; 37: 30-2

2 Jaques $\mathrm{H}$. Royal College launches five year plan to increase applicants to psychiatry. BMJ Careers 2012; 27 March (http://careers.bmj.com/ careers/advice/view-article.html?id=20007042).

3 Sekhri R, Sibbett R. Recruitment in psychiatry: a complex and multifactorial problem. Psychiatrist 2012; 36: 118-9.

4 Barras C, Harris J. Psychiatry recruited you, but will it retain you? Survey of trainees' opinions. Psychiatrist 2012; 36: 71-7.

Sophia A. Bennett, CT3 community old age psychiatry, Bowes Lyon Unit, Lanchester Road Hospital, Durham, UK, email: sophia.bennett@nhs.net

doi: $10.1192 / \mathrm{pb} .37 .4 .148 \mathrm{~b}$

\section{Perhaps a different viewpoint is needed?}

Kelley et $a l^{1}$ raise an interesting point with regard to Foundation Programme placements and subsequent careers in psychiatry, and I applaud their aim. What they look at is whether having experience of psychiatry in the foundation years results in a placement in psychiatry at CT1 level - I would suggest this is not quite the same as influencing a trainee's decision to apply. As suggested in the discussion, I would imagine those keen on a future career in psychiatry are more likely to opt for rotations which contain psychiatry, but how many of these people are dissuaded from applying by a negative experience? Furthermore, how many people go through the application process for a CT post in psychiatry ultimately to be unsuccessful for reasons aside from not having had a taster/ FY post? Perhaps an alternative way of approaching this situation would be to survey the career aspirations of newly qualified FY1s, making note of the FY2 rotations they go through and ultimately which specialties they apply for - in addition to which one they subsequently choose. This method would look for an association between FY2 posts and applications to psychiatry, not just those who are awarded a training post.

1 Kelley TA, Brown J, Carney S. Foundation Programme psychiatry placement and doctors' decision to pursue a career in psychiatry. Psychiatrist 2013; 37: 30-2.

Matthew J. Cordiner, CT3 Psychiatry, Ailsa Hospital, Ayr, UK, email: matthewcordiner@nhs.net

doi: $10.1192 / p b .37 .4 .149$ 